\title{
Antipsychotic Use and Risk of Nursing Home Admission Among Dual-Eligible Medicare Beneficiaries: A Propensity-Matched Study
}

\author{
Rajender R. Aparasu - Satabdi Chatterjee • \\ Hua Chen
}

Published online: 11 February 2015

(c) The Author(s) 2015. This article is published with open access at Springerlink.com

\begin{abstract}
Background Antipsychotic use is associated with serious adverse events in the elderly, and consequently can lead to further healthcare utilization such as nursing home admission.

Objective To evaluate the risk of nursing home admission associated with typical versus atypical antipsychotic use among the US community-dwelling elderly population.

Methods A retrospective cohort design was conducted using Medicare and Medicaid Analytical eXtract (MAX) data from four US states. The cohort included all dualeligible beneficiaries (aged $\geq 65$ years) who initiated antipsychotic treatment during July 2001-December 2003. The risk of nursing home admission during the 6-month follow-up period was evaluated using Cox proportional hazards regression model and extended Cox model stratified on matched pairs based on propensity score, using atypical agents as the reference category.

Results The average risk of nursing home admission was similar among atypical antipsychotic users compared to typical users (hazard ratio [HR] $0.91 ; 95 \%$ confidence interval [CI] 0.81-1.01]) However, the results of extended Cox regression revealed that the effect varied with time; typical users had a moderately lower risk of nursing home admission within the initial 90 days of therapy [HR 0.87 ; $95 \%$ CI 0.77-0.97] but substantial risk was observed for 90-180 days of typical antipsychotic exposure [HR 1.58; $95 \%$ CI 1.08-2.12].
\end{abstract}

R. R. Aparasu $(\bowtie) \cdot S$. Chatterjee $\cdot$ H. Chen Department of Pharmaceutical Health Outcomes and Policy, College of Pharmacy-University of Houston, Texas Medical Center, 1441 Moursund Street, Houston, TX 77030-3407, USA e-mail: rraparasu@uh.edu
Conclusion The study found that, among elderly beneficiaries, typical antipsychotic use was associated with a time-dependent increase in risk of nursing home admission. Given the safety concerns with atypical antipsychotics and their extensive use in the elderly, there is a need to be cautious while prescribing antipsychotics in the vulnerable elderly population.

\section{Key Points}

Antipsychotics, mainly atypical agents, are frequently prescribed in the elderly for the treatment and management of psychoses and behavioral problems in dementia. Use of antipsychotics is associated with adverse events, and consequently can lead to nursing home admission in this population.

The current study evaluated the risk of nursing home admission associated with typical versus atypical antipsychotic use among the dual-eligible elderly in the US.

The findings suggest that typical antipsychotic use is associated with a time-dependent increase in risk of nursing home admission. Given the safety concerns with atypical antipsychotics and their extensive use in the elderly, there is a need to be cautious while prescribing antipsychotics in the vulnerable elderly population.

\section{Introduction}

Antipsychotics are frequently prescribed in the elderly for the treatment and management of psychoses and behavioral 
problems in dementia $[1,2]$. Introduced in the early 1950s, typical antipsychotics such as haloperidol and thioridazine were effective in the treatment of schizophrenia. However, use of these agents was associated with central adverse events like extrapyramidal symptoms, tardive dyskinesia, and sedation [1]. Consequently, atypical antipsychotics such as olanzapine and risperidone were introduced in the 1990s as safer alternatives to typical agents [1-4]. In the past two decades, use of atypical antipsychotics in the elderly has considerably increased, from $15 \%$ of total antipsychotic use in 1996-1998 to $73 \%$ in 2002-2004 [5].

In light of extensive atypical antipsychotic use, results of large clinical trials suggest that the two classes of antipsychotics have comparable effectiveness profiles [6, 7]. These findings question the preference of atypical agents over typical agents. Despite high use, atypical agents are frequently used for off-label indications like depression, obsessive compulsive disorder (OCD), post-traumatic stress disorder (PTSD), and agitation in dementia, among others, with little evidence base [8]. In addition, use of atypical agents has been linked to serious adverse events like cardiometabolic dysfunction, falls/fractures, and cerebrovascular and other cardiovascular events [9-14]. A review of 17 placebo-controlled trials by the US Food Drug and Administration (FDA) revealed a 60-70\% higher risk of mortality with atypical antipsychotics compared to the placebo group [15]. This prompted the FDA to issue a boxed warning on atypical antipsychotics in 2005. Later, based on evidence of increased mortality risk with the use of typical agents, the FDA placed a similar black box warning on typical antipsychotics in 2008 [16]. Overall, the limited evidence base of antipsychotic use together with the differential safety profiles of typical and atypical agents may lead to severe healthcare consequences such as institutionalization of the elderly. Therefore, there is a need to examine the comparative healthcare consequences of the two antipsychotic classes in the elderly population.

Admission to nursing homes constitutes a potential negative outcome in the elderly due to transitioning of patients from independent to dependent care. In 2007, the estimated cost of nursing home care in the US was $\$ 150$ billion [17]. In addition to high healthcare expenditure, nursing home admission has been associated with other adverse consequences like poor quality of care, early mortality for residents, and emotional and psychological distress for caregivers. Studies evaluating nursing home admission among the elderly have identified cognitive impairment, functional decline, and clinical co-morbidities as the major risk factors in diverse healthcare settings [18]. Use of medications can be a potentially modifiable factor that could lead to serious adverse events, and consequently nursing home admission in the elderly.
A study by Zuckerman et al. [19] found that inappropriate medication use was associated with a $31 \%$ higher risk of nursing home admission in a cohort of elderly Medicare beneficiaries. The study further revealed that inappropriate antipsychotic use had a 2.5 -fold higher risk of nursing home admission, whereas other antipsychotic use had more than 4 times increased risk compared to nonuse. Another study by Lopez et al. [20] found that in patients with probable Alzheimer's disease, there was no differential risk of the two antipsychotic classes in the long-term risk of nursing home admission [20]. However, no study has conducted a head-to-head comparison of the two antipsychotic classes in terms of nursing home admission among the elderly, and none focused on the vulnerable dual-eligible elderly population. Dual-eligible beneficiaries (those enrolled in both Medicare and Medicaid) are poorer and less healthy than the general elderly population [21-23]. As a result, they have higher unmet care needs than their non-dual-eligible counterparts [24]. Therefore, the current study sought to examine the risk of nursing home admission in the dual-eligible elderly using antipsychotic medications.

\section{Methods}

\section{Data Source}

The study used 2001-2003 Medicaid and Medicare data from Texas, New York, California, and Florida to achieve the study objective. The above states were chosen to provide large sample sizes and a representative population of the US. The years 2001-2003 were selected to allow for comparable samples for both the drug classes. The Medicaid Analytic Extract (MAX) data consists of four analytic component files-Personal Summary, Prescription, Inpatient, Long Term Care, and Other Services files [25]. The current study involved the use of Personal Summary, Prescription, Inpatient, and Long Term Care files. The Personal Summary file records the demographic characteristics such as the patient's age, gender, race/ethnicity, and eligibility information, among others. The Prescription file consists of variables like therapeutic class of the medications prescribed, their National Drug Codes (NDCs), quantity of service, and days of supply. The Inpatient file captures data elements like admission date, beginning date of service, end date of service, and diagnostic codes for each admission. The Long Term Care file includes information on services provided in long-term care facilities for the Medicaid enrollees. The records in this file are usually weekly or monthly claims. The types of services that apply to this file include mental hospital services for the elderly, nursing facility services, intermediate 
care services for the mentally retarded, and inpatient psychiatric facilities for individuals aged below 21 years.

The Medicare data consists of beneficiary summary files, denominator files, and Medicare Provider Analysis and Review files (MedPAR) [26]. The Beneficiary Summary file is created annually, and contains demographic and entitlement data for its beneficiaries who were (a) a part of the CMS Chronic Condition Data Warehouse (CCW) $5 \%$ sample; (b) documented as being alive for some part of the calendar year accounted for in the Beneficiary Summary file; and (c) enrolled in a Medicare program and entitled to its benefits during the calendar year. The Center of Medicare and Medicaid Services (CMS) denominator file contains enrollment information for all the beneficiaries enrolled in Medicare in a given year. The MedPAR file contains data on inpatient hospital and skilled nursing facility (SNF) utilization of the Medicare beneficiaries. All the Medicare files are linked through a unique identifier. The Medicaid and Medicare files are also linked through a unique patient identifier. Additional information on the data sources can be found elsewhere [27].

\section{Study Sample and Design}

The study population included the Medicare and Medicaideligible enrollees, aged 65 years and older, who initiated treatment with a typical or atypical antipsychotic medication anytime from 1 July 2001-31 December 2003. A patient was defined as a dual-eligible beneficiary whose first prescription of antipsychotic did not include his or her stay in long-term care or a nursing home facility. Inclusion of the beneficiaries in the cohort required that they were continuously eligible for at least 6 months before their first antipsychotic prescription fill date. Only new users of antipsychotic agents were included in the study to protect against selection bias among prevalent users from early symptom emergence, drug intolerance, or treatment failures [28].

\section{Exposure and Outcome Definitions}

Exposure to typical or atypical antipsychotics formed the primary independent variable of our study. The typical antipsychotic cohort comprised users of any of the following agents: loxapine, fluphenazine, triflupromazine, chlorprothixene, haloperidol, chlorpromazine, thioridazine, promazine, trifluperazine, thiothexene, molindone, perphenazine, acetophenazine, mesoridazine, pimozide, and perphenazine-amitriptyline. The atypical antipsychotic cohort consisted of users of clozapine, olanzapine, olanzapine-fluoxetine, risperidone, quetiapine, ziprasidone, or aripiprazole. Use of typical and atypical antipsychotic agents was identified using the corresponding NDCs.
The primary outcome of our study was the time to nursing home admission among the elderly beneficiaries during the 6-month follow-up period. Nursing home admission was defined based on qualified SNF stay using MedPAR files from Medicare, and Long Term Care files from Medicaid. The duration of follow-up was based on previous studies by the authors [29]. Patients were followed till the occurrence of nursing home admission or end of the study period, whichever occurred earlier. Patients were censored if the study period ended without occurrence of the event (180 days), or the treatment was discontinued, the gap between two successive refills of the same class of medications exceeded 30 days, or the patients switched to a different class of antipsychotic, died or were lost to followup. The study allowed switching of antipsychotic agents within the same class. If a patient had only one claim of a particular antipsychotic agent at the index date, he was considered in the cohort throughout the length of supply of that medication. The entire study duration was from 1 July 2001-31 December 2003.

\section{Propensity Score Matching}

The propensity score is defined as a subject's probability to receive a particular treatment conditional on his observed covariates [30]. Since antipsychotic treatment was not randomly assigned to the study population, the two treatment groups differed in various observable and unobserved characteristics. The use of a propensity score aimed to achieve a balance in the observed or known confounders across the typical and atypical users, and thus made the two groups comparable for analysis. Therefore, a propensity score-matched retrospective cohort design was used to examine the association between antipsychotic use and risk of nursing home admission in the above population.

A large number of covariates were included in the calculation of propensity score based on previously published literature, expert opinions, and evidence of their association with the outcome [31]. Those variables were measured for the antipsychotic users based on their health care utilization 6 months before their first antipsychotic fill date and included pretreatment characteristics such as sociodemographics (age, gender, race), clinical characteristics (co-morbidities and co-medications), and severity of illness. Severity of illness was measured as all-cause hospitalization in the previous 6-months of index antipsychotic prescription [32]. Nursing home stay during the 6 months of index prescription date was also included as one of the pre-treatment characteristics among the antipsychotic users.

A logistic regression model was developed using all the above baseline characteristics to obtain propensity scores (likelihood ratio $[\mathrm{LR}]<0.0001$; c statistics 0.71 ). Using the 
resulting propensity scores, patients taking typical antipsychotics were matched with patients taking atypical antipsychotics by GREEDY $5 \rightarrow 1$ matching technique. In this technique, at each phase of the matching process, a "greedy" approach is used, whereby a control subject is matched to a treated subject even if it better serves as a match for another treated subject [33]. This technique reduces matched-pair bias caused by incomplete and inexact matching [34]. In the present study, the subjects treated with typical agents were first matched to the subjects treated with atypical agents on the first five digits of the propensity score. For those treated subjects who remained unmatched, matching was done based on the first four digits of the propensity score. This process was repeated until the subjects in both the treatment groups were matched on the first digit of the propensity score. Subjects in the two treatment groups that remained unmatched were excluded. If more than one control was found that matched to a case, the control was selected at random.

\section{Statistical Analysis}

The differences in various pretreatment characteristics between the two groups were evaluated using a chi-square test for categorical variables and $t$ test for continuous variables before and after matching. Survival analysis was then performed on the matched cohort to assess the risk of nursing home admission between typical versus atypical antipsychotic users. Kaplan-Meier survival plots were created to depict the crude (unadjusted) relationships between typical antipsychotic use versus atypical antipsychotic use and time to nursing home admission. Pairwise log rank tests were used to compare survival curves for statistical difference. An a priori value of 0.05 was used to examine the statistical significance.

Cox proportional-hazards regression model stratified on matched pairs was used to examine the risk of nursing home admission between typical users and atypical users, and the corresponding hazard ratios (HRs) were obtained. Stratified Cox proportional-hazard model was applied using the STRATA option of PROC PHREG to account for matched pair design [33, 34]. Prior to using the Cox regression model, the Proportional Hazards (PH) assumption for the model was checked by including the interaction term between the independent variables and log of time to nursing home admission. The PH assumption for antipsychotic use was not met at the significance level of 0.05 , indicating that the treatment effect was not constant over time. In order to adjust for time in our analysis, extended Cox models were used with heavy side function $[35,36]$. Models of nursing home admission within the first 90 days and from 90-180 days were developed. The cut-off point of 90 days was selected based on the intersection of the
Kaplan Meier curves of the two drug classes. All analyses were performed using SAS version 9.2.

\section{Results}

Analysis of Medicaid-Medicare dual-eligible data revealed that between 2001 and 2003 there were 60,131 users of antipsychotic agents (49,200 atypical and 10,931 typical users) in the outpatient population of dual-eligible beneficiaries. The matched cohort had a total of 20,818 patients $(10,919$ atypical and 10,919 typical users). Table 1 presents the baseline characteristics of the users of typical and atypical antipsychotic agents before and after propensity score matching. It can also be seen from the table that, before matching, the typical and atypical users differed in a large number of the pretreatment characteristics. After matching, nearly all the pretreatment variables were balanced across the two treatment groups. Figure 1 presents the distribution of the propensity scores before matching. Figure 2 presents the distribution of propensity scores after matching. Thus, propensity score helped achieve a balance in the majority of the pretreatment characteristics in the two treatment groups.

Overall, there were 2,214 patients who experienced nursing home admission during the follow-up period. There were 1,275 events $(11.66 \%)$ in the atypical cohort and $939(8.59 \%)$ events in the typical cohort. Figure 3 presents the Kaplan Meier curves that depict the unadjusted association across the antipsychotic classes with respect to nursing home admission in the elderly beneficiaries. The Kaplan Meier curve suggests that there was no difference in risk of nursing home admission across typical and atypical use among the beneficiaries $(p=0.88)$.

Table 2 presents the results of Cox proportional hazards regression of antipsychotic use and time to nursing home admission in the above population. Results of Cox regression in the above cohort suggest that the average risk of nursing home admission was similar among typical antipsychotic users compared to atypical users (HR 0.91; $95 \%$ confidence interval [CI] 0.81-1.01). However, due to violation of the $\mathrm{PH}$ assumption, the extended Cox regression was used. The findings suggest that within the first 90 days of treatment, there was a moderately lower risk of nursing home admission among typical users $(<90$ days: HR 0.87; $95 \%$ CI 0.77-0.97). However, the risk substantially increased with prolonged typical antipsychotic treatment [90-180 days: HR 1.58; $95 \%$ CI 1.08-2.12].

\section{Discussion}

The current study examined the risk of nursing home admission due to use of antipsychotics in the elderly. Both 
Table 1 Baseline characteristics of typical and atypical antipsychotic users among elderly dual-eligible beneficiaries

\begin{tabular}{|c|c|c|c|c|c|c|}
\hline Characteristics & $\begin{array}{l}\text { Atypical antipsychotic } \\
\text { users in unmatched } \\
\text { cohort }(n=49,200)\end{array}$ & $\begin{array}{l}\text { Typical antipsychotic } \\
\text { users in unmatched } \\
\text { cohort }(n=10,931)\end{array}$ & $p$ value & $\begin{array}{l}\text { Atypical antipsychotic } \\
\text { users in matched } \\
\text { cohort }(n=10,919)\end{array}$ & $\begin{array}{l}\text { Typical antipsychotic } \\
\text { users in matched } \\
\text { cohort }(n=10,919)\end{array}$ & $p$ value \\
\hline Age (y) & 79.37 (8.37) & $79.33(8.56)$ & 0.69 & $79.35(8.32)$ & $79.23(8.55)$ & 0.35 \\
\hline Gender $[n(\%)]$ & & & $<.0001 *$ & & & 0.83 \\
\hline Male & $14,049(28.55)$ & $3,732(34.14)$ & & 3,707 (33.95) & $3,722(37.09)$ & \\
\hline Female & $35,151(71.45)$ & $7,199(65.86)$ & & $7,212(66.05)$ & $7,197(65.91)$ & \\
\hline $\operatorname{Race}[n(\%)]$ & & & $<.0001 *$ & & & 0.30 \\
\hline White & $22.393(45.51)$ & $4,218(38.59)$ & & $4,205(38.51)$ & $4,218(38.63)$ & \\
\hline Black & 4,823 (9.8) & $1,416(12.95)$ & & $1,486(13.61)$ & $1,410(12.91)$ & \\
\hline Others & $21,984(44.68)$ & $5,297(48.46)$ & & $5,228(47.88)$ & $5,291(48.46)$ & \\
\hline Region & & & $<.0001 *$ & & & 0.98 \\
\hline New York & 13,799 (28.05) & $2,336(21.37)$ & & $2,321(21.26)$ & $2,334(21.38)$ & \\
\hline Florida & $9,722(19.76)$ & $1,459(13.35)$ & & $1,445(13.23)$ & $1,459(13.36)$ & \\
\hline California & $18,792(38.20)$ & $5,469(50.03)$ & & $5,475(50.14)$ & $5,461(50.01)$ & \\
\hline Texas & $6,887(14.00)$ & $1,667(15.25)$ & & $1,678(15.37)$ & $1,665(15.25)$ & \\
\hline $\begin{array}{l}\text { Year of cohort } \\
\text { entry }\end{array}$ & & & $<.0001 *$ & & & 0.62 \\
\hline 2001 & 38,107 (77.45) & $9,382(85.83)$ & & 9,357 (85.69) & $9,370(85.81)$ & \\
\hline 2002 & $10,451(21.24)$ & $1,454(13.30)$ & & $1,453(13.31)$ & $1,454(13.32)$ & \\
\hline 2003 & $642(1.30)$ & $95(0.87)$ & & 109 (1.00) & $95(0.87)$ & \\
\hline \multicolumn{7}{|c|}{ Hospitalization in past 6 months $[n(\%)]$} \\
\hline Yes & $13,262(23.96)$ & $2,670(24.43)$ & $<.0001 *$ & $2,717(24.88)$ & $2,661(24.39)$ & 0.38 \\
\hline \multicolumn{7}{|c|}{ Nursing home admission in past 6 months $[n(\%)]$} \\
\hline Yes & $6,819(13.86)$ & $971(8.88)$ & $<.0001 *$ & $991(9.08)$ & $970(8.88)$ & 0.62 \\
\hline \multicolumn{7}{|c|}{ Medical history in past 6 months $[n(\%)]$} \\
\hline Hypertension & $5,954(12.10)$ & $1,117(10.22)$ & $<.0001 *$ & $1,156(10.59)$ & $1,114(10.20)$ & 0.35 \\
\hline $\mathrm{CHD}$ & $2,807(5.71)$ & $509(4.66)$ & $<.0001^{*}$ & $548(5.02)$ & $508(4.65)$ & 0.21 \\
\hline $\mathrm{CHF}$ & $3,016(6.13)$ & $611(5.59)$ & $\mathbf{0 . 0 3} *$ & $616(5.64)$ & $610(5.59)$ & 0.86 \\
\hline AMI & $562(1.14)$ & $125(1.14)$ & 0.99 & $131(1.20)$ & $124(1.14)$ & 0.66 \\
\hline Dysrhythmia & 2,259 (4.59) & 447 (4.09) & $0.02 *$ & $432(3.96)$ & $446(4.08)$ & 0.63 \\
\hline $\begin{array}{l}\text { Circulatory } \\
\text { disorder }\end{array}$ & $1,099(2.23)$ & $210(1.92)$ & $0.04 *$ & $204(1.87)$ & 209 (1.91) & 0.80 \\
\hline $\begin{array}{l}\text { Thromboembolic } \\
\text { disorder }\end{array}$ & $288(0.59)$ & $53(0.48)$ & 0.21 & $46(0.42)$ & $53(0.49)$ & 0.48 \\
\hline Diabetes & $3,208(6.52)$ & $657(6.01)$ & $0.04 *$ & $674(6.17)$ & $656(6.01)$ & 0.61 \\
\hline Cerebral & $1,990(4.04)$ & $380(3.48)$ & 0.006* & $372(3.41)$ & $380(3.48)$ & 0.77 \\
\hline Fracture & $629(1.28)$ & $80(0.73)$ & $<.0001 *$ & $85(0.78)$ & $80(0.73)$ & 0.69 \\
\hline COPD & $2,608(5.30)$ & 489 (4.47) & $0.0004 *$ & $495(4.53)$ & 487 (4.46) & 0.79 \\
\hline Falls & $80(0.16)$ & $8(0.07)$ & $\mathbf{0 . 0 3} *$ & $11(0.10)$ & $8(0.07)$ & 0.49 \\
\hline Thyroid & $5,023(10.21)$ & $1,011(9.25)$ & $0.003 *$ & $1,012(9.27)$ & $1,011(9.26)$ & 0.98 \\
\hline Renal failure & 782 (1.59) & $181(1.66)$ & 0.62 & $173(1.58)$ & $181(1.66)$ & 0.66 \\
\hline Renal disease & 2,889 (5.87) & $553(5.06)$ & $0.0009 *$ & $539(4.94)$ & $552(5.06)$ & 0.68 \\
\hline Liver disease & $429(0.87)$ & $93(0.85)$ & 0.83 & $86(0.79)$ & $93(0.85)$ & 0.59 \\
\hline Gastric & 2,898 (5.89) & $621(5.68)$ & 0.39 & $614(5.62)$ & $617(5.65)$ & 0.93 \\
\hline Ulcer & $860(1.75)$ & $162(1.48)$ & 0.05 & 159 (1.46) & $162(1.48)$ & 0.87 \\
\hline Cancer & $1,022(2.08)$ & $336(3.07)$ & $<.0001 *$ & 359 (3.29) & 326 (2.99) & 0.20 \\
\hline Cataract & $35(0.07)$ & $4(0.04)$ & 0.27 & $4(0.04)$ & $4(0.04)$ & 1.00 \\
\hline Glaucoma & $123(0.25)$ & $26(0.24)$ & 0.82 & $25(0.23)$ & $26(0.24)$ & 0.89 \\
\hline Anemia & $1,690(3.43)$ & $323(2.95)$ & $0.01 *$ & 324 (2.97) & $322(2.95)$ & 0.94 \\
\hline Osteoporosis & $427(0.87)$ & $49(0.45)$ & $<.0001^{*}$ & $55(0.50)$ & $49(0.45)$ & 0.56 \\
\hline
\end{tabular}


Table 1 continued

\begin{tabular}{|c|c|c|c|c|c|c|}
\hline Characteristics & $\begin{array}{l}\text { Atypical antipsychotic } \\
\text { users in unmatched } \\
\text { cohort }(n=49,200)\end{array}$ & $\begin{array}{l}\text { Typical antipsychotic } \\
\text { users in unmatched } \\
\text { cohort }(n=10,931)\end{array}$ & $p$ value & $\begin{array}{l}\text { Atypical antipsychotic } \\
\text { users in matched } \\
\text { cohort }(n=10,919)\end{array}$ & $\begin{array}{l}\text { Typical antipsychotic } \\
\text { users in matched } \\
\text { cohort }(n=10,919)\end{array}$ & $p$ value \\
\hline RA & $113(0.23)$ & $17(0.16)$ & 0.13 & $18(0.16)$ & $17(0.16)$ & 0.87 \\
\hline Back pain & $379(0.77)$ & $55(0.50)$ & 0.003* & $61(56)$ & $55(0.50)$ & 0.58 \\
\hline Dyslipidemia & $683(1.39)$ & $100(0.91)$ & $<.0001 *$ & $97(0.89)$ & $100(0.92)$ & 0.83 \\
\hline Obesity & $139(0.28)$ & $21(0.19)$ & 0.09 & $25(0.23)$ & $21(0.19)$ & 0.56 \\
\hline HIV & $29(0.06)$ & $10(0.09)$ & 0.23 & $11(0.10)$ & $9(0.08)$ & 0.66 \\
\hline Pneumonia & $1,608(3.27)$ & $333(3.05)$ & 0.24 & $311(2.85)$ & $333(3.05)$ & 0.38 \\
\hline $\begin{array}{l}\text { Parkinson's } \\
\text { disease }\end{array}$ & $433(0.88)$ & $43(0.39)$ & $<.0001 *$ & $53(0.49)$ & $43(0.39)$ & 0.31 \\
\hline Endocarditis & $394(0.80)$ & $67(0.61)$ & $\mathbf{0 . 0 4} *$ & $71(0.65)$ & $67(0.61)$ & 0.73 \\
\hline Suicide & $3(0.01)$ & $0(0)$ & 0.41 & $0(0)$ & $0(0)$ & - \\
\hline Alcoholism & $444(0.90)$ & $62(0.57)$ & $0.0005^{*}$ & $53(0.49)$ & $62(0.57)$ & 0.40 \\
\hline EPS & $46(0.09)$ & $11(0.10)$ & 0.83 & $9(0.08)$ & $11(0.10)$ & 0.66 \\
\hline \multicolumn{7}{|l|}{$\begin{array}{l}\text { Psychiatric } \\
\quad \text { disorders }[n(\%)]\end{array}$} \\
\hline Anxiety & $434(0.88)$ & $50(0.46)$ & $<.0001 *$ & $54(0.49)$ & $50(0.46)$ & 0.69 \\
\hline Conduct disorder & $13(0.03)$ & $2(0.02)$ & 0.63 & $5(0.05)$ & $2(0.02)$ & 0.26 \\
\hline Dementia & $2,780(5.65)$ & $392(3.59)$ & $<.0001 *$ & $393(3.60)$ & $392(3.59)$ & 0.97 \\
\hline Mood disorder & $1,678(3.41)$ & $138(1.26)$ & $<.0001 *$ & $176(1.61)$ & $138(1.26)$ & $\mathbf{0 . 0 3} *$ \\
\hline Schizophrenia & $955(1.94)$ & $100(0.91)$ & $<.0001 *$ & $114(1.04)$ & $100(0.92)$ & 0.34 \\
\hline $\begin{array}{l}\text { Other psychiatric } \\
\text { disorders }\end{array}$ & $409(0.83)$ & $67(0.61)$ & $\mathbf{0 . 0 2} *$ & $77(0.71)$ & $67(0.61)$ & 0.40 \\
\hline \multicolumn{7}{|c|}{ Medication history in past 6 months } \\
\hline Cardiovascular & $32,093(65.23)$ & $6,990(63.95)$ & $0.01 *$ & $6,966(63.80)$ & $6,984(63.96)$ & 0.79 \\
\hline Antidiabetic & $10,263(20.86)$ & $2,373(21.71)$ & $\mathbf{0 . 0 4} *$ & $2,349(21.51)$ & $2,372(21.72)$ & 0.71 \\
\hline Analgesics & $26,169(53.19)$ & $5,790(52.97)$ & 0.68 & $5,831(53.40)$ & $5,782(52.95)$ & 0.51 \\
\hline Estrogen & $3,364(6.84)$ & $584(5.34)$ & $<.0001 *$ & $580(5.31)$ & $584(5.35)$ & 0.90 \\
\hline Antihistamine & $8,641(17.56)$ & $2,227(20.37)$ & $<.0001 *$ & $2,282(20.90)$ & $2,222(20.35)$ & 0.32 \\
\hline Gastrointestinal & $22,879(46.50)$ & $4,945(45.24)$ & $\mathbf{0 . 0 2} *$ & 4,902 (44.89) & $4,934(45.19)$ & 0.66 \\
\hline Anticoagulant & $11,010(22.38)$ & $2,195(20.08)$ & $<.0001 *$ & $2,242(20.53)$ & $2,193(20.08)$ & 0.41 \\
\hline Corticosteroids & $5,058(10.28)$ & $1,184(10.83)$ & 0.09 & $1,182(10.83)$ & $1,180(10.81)$ & 0.97 \\
\hline Bronchodilators & $6,272(12.75)$ & $1,483(13.57)$ & $\mathbf{0 . 0 2} *$ & $1,482(13.57)$ & $1,480(13.55)$ & 0.97 \\
\hline Anti-infective & $23,243(47.24)$ & $5,272(48.23)$ & 0.06 & $5,305(48.59)$ & $5,262(48.19)$ & 0.56 \\
\hline Diuretics & $12,815(26.05)$ & $2,879(26.34)$ & 0.53 & $2,888(26.45)$ & $2,876(26.34)$ & 0.85 \\
\hline Anticancer & $2,491(5.06)$ & $688(6.29)$ & $<.0001 *$ & $722(6.61)$ & $677(6.20)$ & 0.21 \\
\hline Anticholinergic & $3,450(7.01)$ & $841(7.69)$ & $0.01 *$ & $832(7.62)$ & 838 (7.67) & 0.88 \\
\hline Alcohol drug & $10(0.02)$ & $4(0.04)$ & 0.31 & $3(0.03)$ & $4(0.04)$ & 0.71 \\
\hline Ophthalmic & $11,678(23.74)$ & 2,509 & 0.08 & $2,524(23.12)$ & $2,507(22.96)$ & 0.78 \\
\hline Thyroid & $5,023(10.21)$ & $1,011(9.25)$ & $0.0025 *$ & $1,012(9.27)$ & $1,011(9.26)$ & 0.98 \\
\hline Antismoking & $101(0.21)$ & $17(0.16)$ & 0.29 & $18(0.16)$ & $17(0.16)$ & 0.86 \\
\hline Endocrine & $112(0.23)$ & $29(0.27)$ & 0.46 & $23(0.21)$ & $28(0.26)$ & 0.48 \\
\hline Hypnotics & $9,473(19.25)$ & $1,664(15.22)$ & $<.0001 *$ & $1,644(15.06)$ & $1,662(15.22)$ & 0.73 \\
\hline Antidepressant & $18,368(37.33)$ & $2,643(24.18)$ & $<.0001 *$ & $2,660(24.36)$ & $2,643(24.21)$ & 0.79 \\
\hline Anticonvulsant & $6,821(13.86)$ & 1,087 (9.94) & $<.0001 *$ & $1,086(9.95)$ & $1,086(9.95)$ & 1.00 \\
\hline Lithium & $260(0.53)$ & $24(0.22)$ & $<.0001 *$ & $28(0.26)$ & $24(0.22)$ & 0.58 \\
\hline Anti-anxiety & $10,958(22.27)$ & $2,061(18.85)$ & $<.0001 *$ & $2,029(18.58)$ & $2,059(18.86)$ & 0.60 \\
\hline
\end{tabular}


Table 1 continued

\begin{tabular}{llllll}
\hline Characteristics & $\begin{array}{l}\text { Atypical antipsychotic } \\
\text { users in unmatched } \\
\text { cohort }(n=49,200)\end{array}$ & $\begin{array}{l}\text { Typical antipsychotic } \\
\text { users in unmatched } \\
\text { cohort }(n=10,931)\end{array}$ & $p$ value & $\begin{array}{l}\text { Atypical antipsychotic } \\
\text { users in matched } \\
\text { cohort }(n=10,919)\end{array}$ & $\begin{array}{l}\text { Typical antipsychotic } \\
\text { users in matched } \\
\text { cohort }(n=10,919)\end{array}$ \\
\hline Stimulants & $143(0.29)$ & $16(0.15)$ & $\mathbf{0 . 0 0 8}^{*}$ & $11(0.10)$ & $16(0.15)$ \\
\hline
\end{tabular}

$C H D$ coronary heart disease, $C H F$ chronic heart failure, $A M I$ acute myocardial infarction, $C O P D$ chronic obstructive pulmonary disease, $R A$ rheumatoid arthritis, $H I V$ human immunodeficiency virus, EPS extrapyramidal syndrome

* $p$ value significant at $<0.05$

Fig. 1 Distribution of propensity scores in users of atypical and typical antipsychotics before propensity score matching

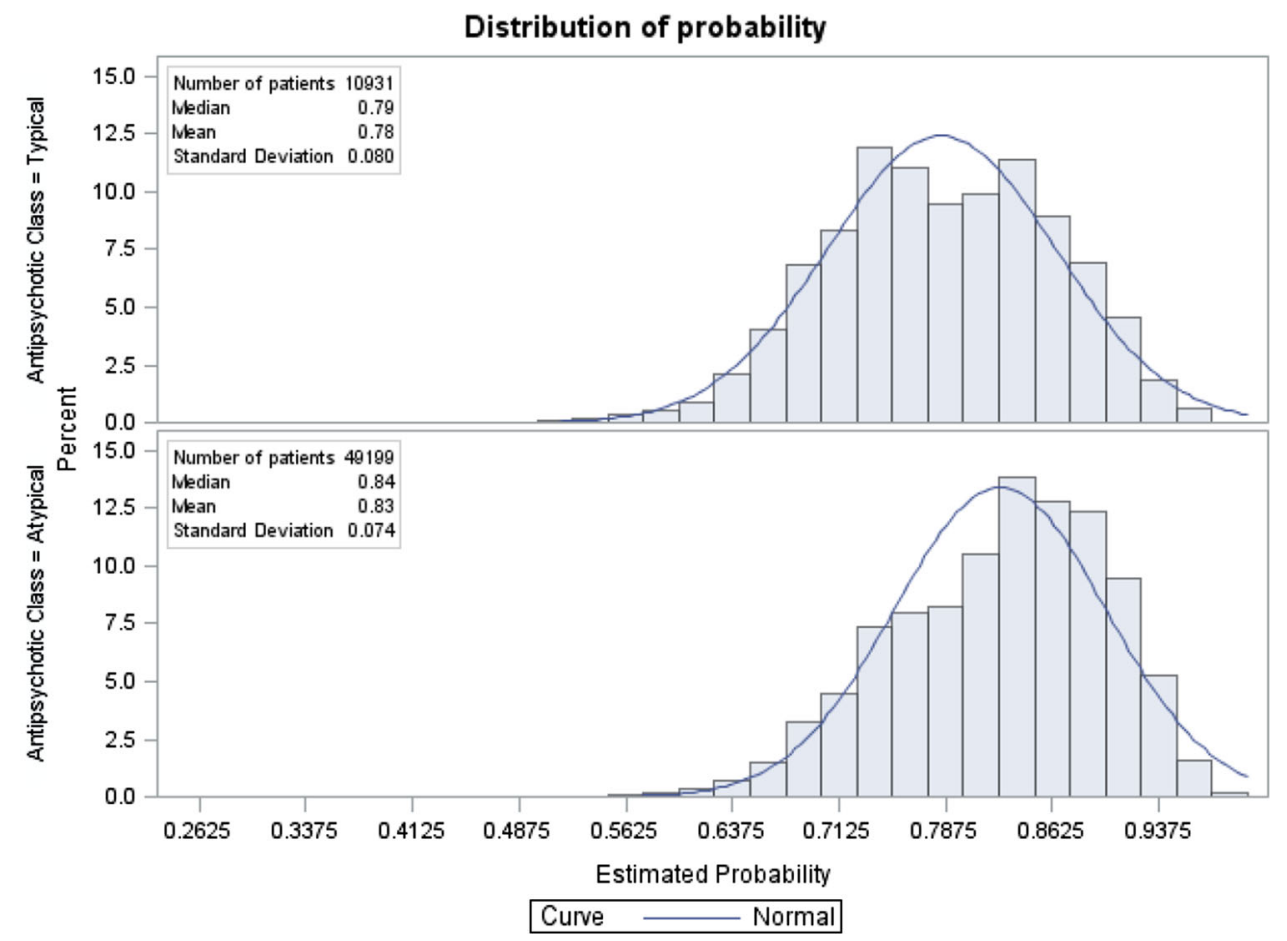

typical and atypical antipsychotic agents are associated with adverse effects in the elderly. The differential safety profiles of typical and atypical antipsychotic agents can have healthcare consequences such as nursing home admission. This study found that, after controlling for potential confounders, typical antipsychotic use was associated with a time-dependent increase in risk of nursing home admission compared to atypical use. In the initial phase of treatment, typical antipsychotics have a slightly lower risk of nursing home admission (13\%); however, with prolonged use of typical agents, the risk of nursing home admission increases to $58 \%$.

The study by Lopez et al. [20] found that there is no difference in nursing home admission among users of typical and atypical antipsychotics in patients with probable Alzheimer's disease. However, the study did not compare the two classes directly, and focused on longterm nursing home admission among probable Alzheimer's patients. The study by Zuckerman et al. [19] examined the 1-year risk of nursing home admission among users of the inappropriate versus other antipsychotics, and found a $70 \%$ higher risk with use of other antipsychotics. This study evaluated the risk of nursing home admission during 6 months of antipsychotic use and found that typical users had a time-dependent increase in nursing home admission. However, the current study may not be directly comparable with previous studies owing to differences in exposure definition, outcomes measurement, and study sample.

The study by Lopez et al. [20] further revealed that, after controlling for underlying patient conditions like psychosis and agitation, the risk of nursing home admission was no longer significant for either class of antipsychotics. Zuckerman et al. [19] also suggested the possibility of an indication bias to explain the high risk associated with use of other antipsychotics compared to inappropriate antipsychotics. The current study controlled for psychiatric co-morbidities like anxiety, dementia, mood disorders, and schizophrenia, which necessitate the use of antipsychotic medications in the study population, and found that typical 
Fig. 2 Distribution of propensity scores in users of atypical and typical antipsychotics after propensity score matching

\section{Distribution of probability}

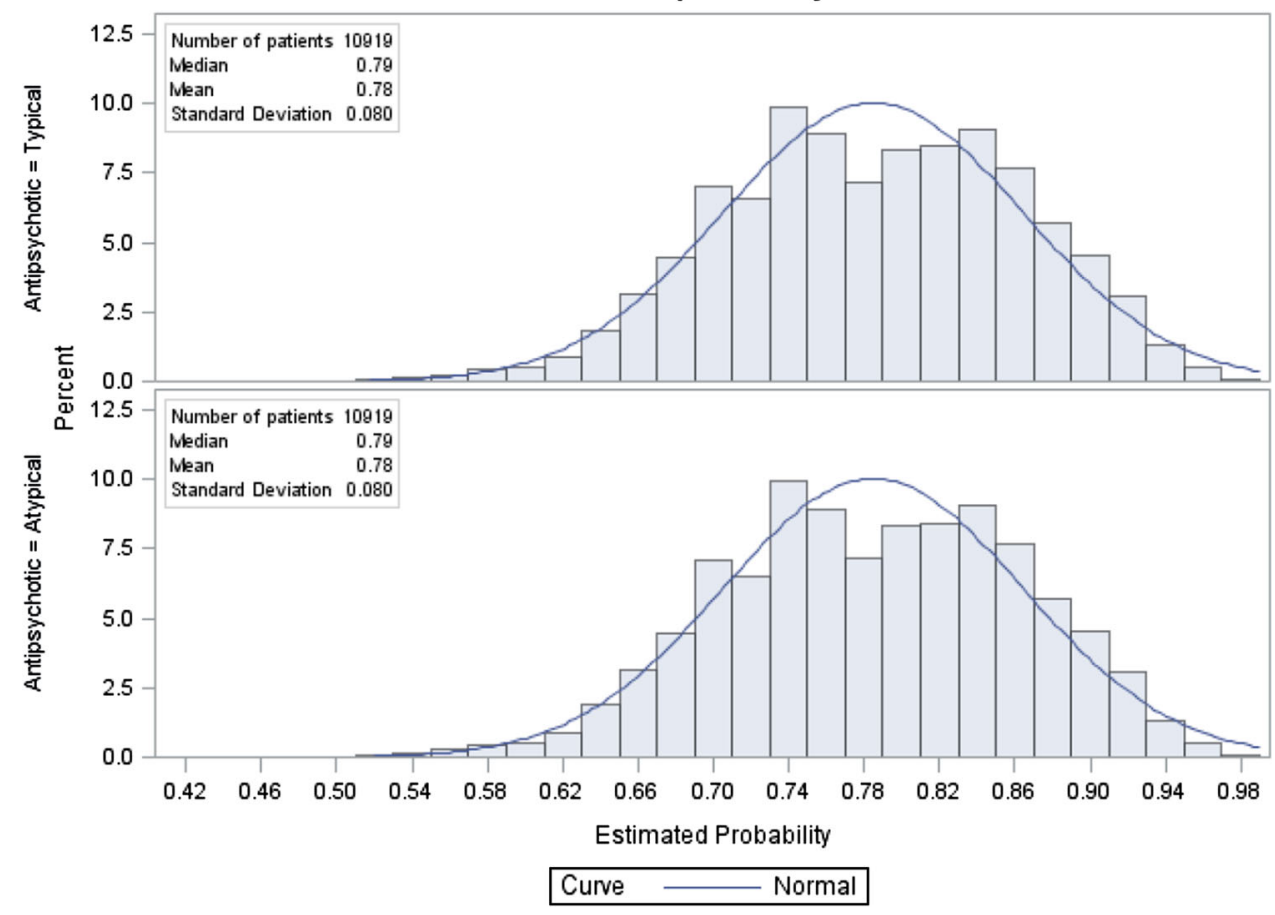

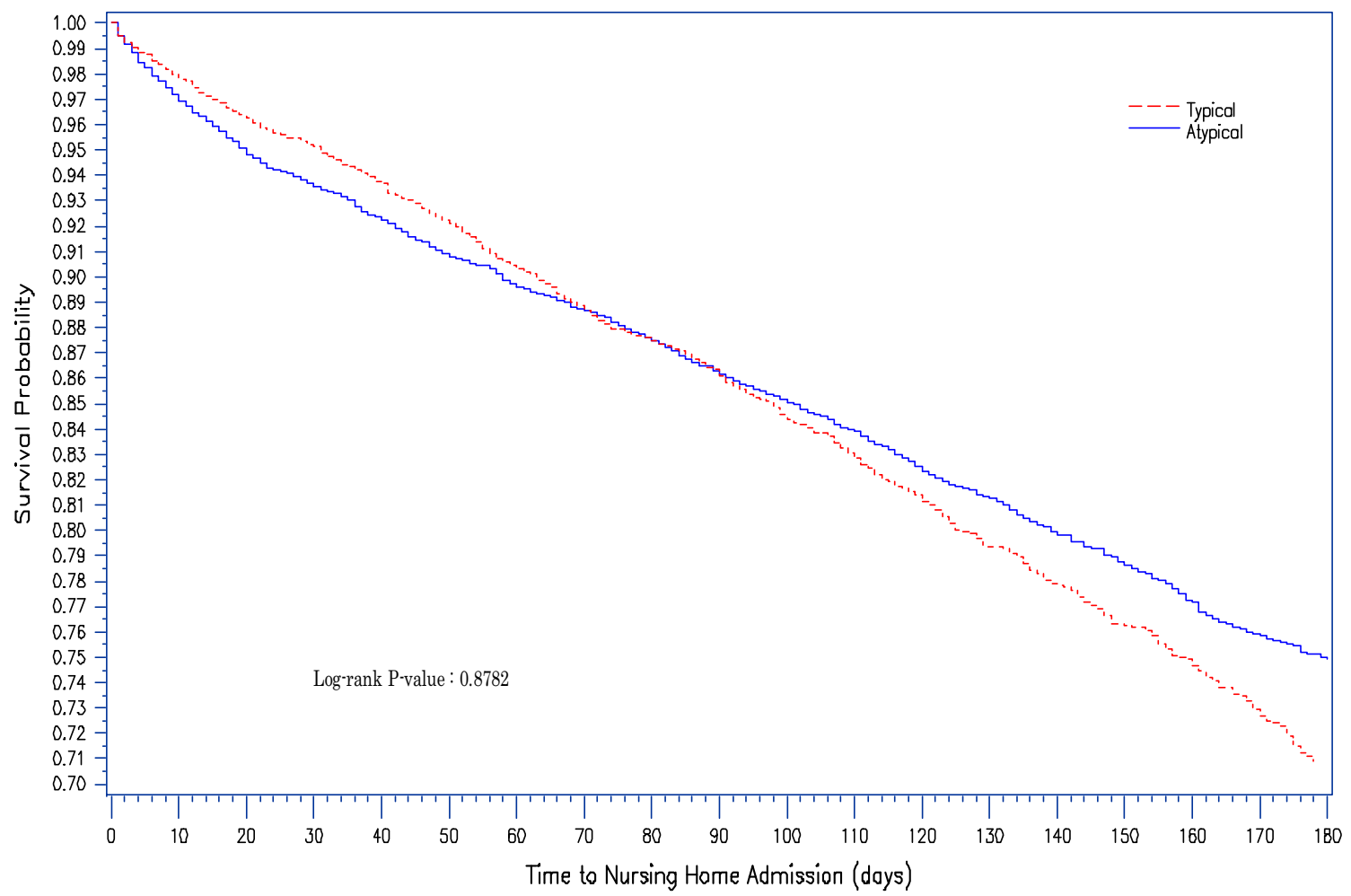

Fig. 3 Kaplan-Meier plot of crude association between users of typical and atypical antipsychotics and risk of nursing home admission

antipsychotic use had a differential risk of nursing home admission.

Several pharmacologic mechanisms can explain the higher risk of nursing home admission observed with prolonged exposure to typical antipsychotics (90-180 days). Long-term use of typical antipsychotics could lead to extrapyramidal syndrome. The relatively higher dopaminergic activity of typical antipsychotics 
Table 2 Cox proportional hazard model for risk of nursing home admission in typical antipsychotic users versus atypical antipsychotic users among community-dwelling elderly ${ }^{\mathrm{a}}$

\begin{tabular}{lccc}
\hline Variables & Hazard ratio & $95 \%$ CI & $p$ value \\
\hline $\begin{array}{l}\text { Multivariable analysis for antipsychotic treatment } \\
\text { Atypical }\end{array} 1.00$ & 0.91 & $0.81-1.01$ & 0.08 \\
Typical & & & \\
Multivariable analysis by time periods & & \\
$<90$ days of therapy & 0.87 & $0.77-0.97$ & $\mathbf{< 0 . 0 1 *}$ \\
$90-180$ days of therapy & 1.58 & $1.08-2.12$ & $<\mathbf{0 . 0 2} *$ \\
\hline
\end{tabular}

a Atypical antipsychotics formed reference category

* Significant at $p<0.05$

compared to atypical agents has also been associated with elevated prolactin levels, which in turn decreases the bone mineral density, and may lead to falls/fractures [37, 38]. Together, these adverse events could lead to nursing home admission among typical users. The moderately lower risk (13\%) during the initial period of typical use (0-90 days) may possibly be due to variable induction/latency periods or serotonergic/histaminergic receptor blockade [39]. The current study did not examine the specific reasons for nursing home admission in the study population. Future studies are therefore needed to better understand the consequences of antipsychotic treatment in elderly. However, given the high risk of nursing home admission with prolonged typical use (90-180 days) and safety concerns with atypical agents, there is a need to be cautious while prescribing antipsychotics in the elderly. Consequently, clinicians should consider prescribing the lowest dose of antipsychotics for the shortest duration, whenever possible, and avoid concomitant prescription of other psychotropic medications that could predispose the residents to additional risk.

This study had several strengths. The propensity-matched retrospective cohort design involved a large number of dual-eligible elderly users of antipsychotics. The model included several potential confounders that could be related to antipsychotic treatment and risk of nursing home admission. Only new users of antipsychotics were included in the study cohort to minimize prevalence bias [28]. Additionally, the study focused on the dual-eligible population, which represents one of the most understudied populations and which has very high unmet long-term care needs [24].

Several study limitations should be acknowledged. Since computer-recorded information was used to capture data, we could not ascertain whether the subjects actually used their dispensed medicines. The diseases and outcome measurements were based on diagnostic data in medical claims. Incomplete records submitted by providers together with inaccurate demographic information and clinical details in the ICD-9-CM system may further limit the accuracy of administrative data. A major limitation of the current study was lack of outpatient data among the community-dwelling beneficiaries. The current study only used inpatient data to capture the patients' baseline characteristics; this may have provided a limited picture of the patients' underlying illnesses since many patients are not hospitalized. Additionally, variables included in the propensity score calculation were limited to those available in the data source; there is thus a possibility that unmeasured confounders such as tobacco use, nutrition, health status, cognitive and functional limitations, and behavioral variables might have affected the study findings [40]. Also, results obtained from propensity score matching can only be applicable to the final matched cohort of the population studied due to incomplete matching. Although nursing home admission addresses the healthcare impact of drug utilization, it is only a generic measure, and a social construct; future studies are needed to evaluate the specific reason for nursing home admission among typical versus atypical users. Additionally, the study focused on the vulnerable dual-eligible beneficiaries; the findings may not be extrapolated to other populations or settings.

\section{Conclusions}

Antipsychotic-induced adverse events constitute a significant public health concern owing to its associated morbidity and mortality in the elderly. The current propensity score-matched retrospective cohort study found that use of typical antipsychotics was associated with a time-dependent risk of nursing home admission. The risk however increased with prolonged typical antipsychotic treatment. The above study findings suggest that multiple pharmacologic mechanisms might play an important role in adverse events, which could lead to nursing home admission. The study reinforces the need to evaluate the contributory factors of nursing home placement with antipsychotic use among the elderly. Given the extensive use of antipsychotic agents in the elderly, future studies involving the short-term and long-term risk-benefit profiles are needed to evaluate the role of antipsychotics in geriatric pharmacotherapy.

Acknowledgments This research was supported by a Grant from the Agency for Healthcare Research and Quality (1R03HS01692001A1).

Open Access This article is distributed under the terms of the Creative Commons Attribution Noncommercial License which permits any noncommercial use, distribution, and reproduction in any medium, provided the original author(s) and the source are credited. 


\section{References}

1. Bagnall AM, Jones L, Ginnelly L, et al. A systematic review of atypical antipsychotic drugs in schizophrenia. Health Technol Assess. 2003;7:1-193.

2. Jeste DV, Dolder CR, Nayak GV, et al. Atypical antipsychotics in elderly patients with dementia or schizophrenia: review of recent literature. Harv Rev Psychiatry. 2005;13(6):340-51.

3. Carson S, McDonagh MS, Peterson K. A systematic review of the efficacy and safety of atypical antipsychotics in patients with psychological and behavioral symptoms of dementia. J Am Geriatr Soc. 2006;54(2):354-61.

4. Alexopoulos GS, Streim J, Carpenter D, et al. Expert consensus panel for using antipsychotic drugs in older patients. Using antipsychotic agents in older patients. J Clin Psychiatry. 2004;65(Suppl 2):5-99.

5. Jano E, Chen H, Johnson ML, et al. Antipsychotic utilization and expenditure trends among elderly persons. Psychiatr Serv. 2007;58(11):1400.

6. Lieberman JA, Stroup TS, McEvoy JP, Clinical Antipsychotic Trials of Intervention Effectiveness (CATIE) Investigators, et al. Effectiveness of antipsychotic drugs in patients with chronic schizophrenia. N Engl J Med. 2005;353:1209-23.

7. Jones PB, Barnes TRE, Davies L, et al. Randomized controlled trial of the effect on quality of life of second- vs. first-generation antipsychotic drugs in schizophrenia. Cost Utility of the Latest Antipsychotic Drugs in Schizophrenia Study (CUtLASS 1). Arch Gen Psychiatry. 2006;63:1079-87.

8. Shekelle P, Maglione M, Bagley S, et al. Efficacy and comparative effectiveness of off-label use of atypical antipsychotics. Comparative effectiveness review No. 6. (Prepared by the Southern California/RAND Evidence-based Practice Center under Contract No. 290-02-0003). Rockville, MD: Agency for Healthcare Research and Quality. January 2007. Available at: http://www. effectivehealthcare.ahrq.gov/reports/final.cfm. Accessed Oct 2009.

9. Kirshner HS. Controversies in behavioral neurology: the use of atypical antipsychotic drugs to treat neurobehavioral symptoms in dementia. Curr Neurol Neurosci Rep. 2008;8:471-4.

10. Trifiro G, Spina E, Gambassi G. Use of antipsychotics in elderly patients with dementia: do atypical and conventional agents have a similar safety profile? Pharmacol Res. 2009;59:1-12.

11. Henderson DC. Managing weight gain and metabolic issues in patients treated with atypical antipsychotics. J Clin Psychiatry. 2008;69:e04.

12. Baker RA, Pikalov A, Tran QV, et al. Atypical antipsychotic drugs and diabetes mellitus in the US Food and Drug Administration adverse event database: a systematic bayesian signal detection analysis. Psychopharmacol Bull. 2009;42:11-31.

13. Ray WA, Chung CP, Murray KT, et al. Atypical antipsychotic drugs and the risk of sudden cardiac death. N Engl J Med. 2009;360:225-35.

14. Steinberg M, Lyketsos CG. Atypical antipsychotic use in patients with dementia: managing safety concerns. Am J Psychiatry. 2012;169(9):900-6.

15. Food and Drug Administration Public Health Advisory: deaths with antipsychotics in elderly patients with behavioral disturbances [online]. Available at: http://www.fda.gov/Drugs/Drug Safety/PostmarketDrugSafetyInformationforPatientsandProviders/ DrugSafetyInformationforHeathcareProfessionals/PublicHealth Advisories/ucm053171.htm. Accessed 3 Dec 2010.

16. Food and Drug Administration Public Health Advisory. Information for Healthcare Professionals: conventional antipsychotics [online]. Available at: http://www.fda.gov/Drugs/DrugSafety/ PostmarketDrugSafetyInformationforPatientsandProviders/ucm 124830.htm. Accessed 3 Dec 2010.
17. Gaugler JE, Duval S, Anderson KA, et al. Predicting nursing home admission in the US: a meta-analysis. BMC Geriatr. 2007;19(7):13-27.

18. Bharucha AJ, Pandav R, Shen C, et al. Predictors of nursing facility admission: a 12-year epidemiological study in the United States. J Am Geriatr Soc. 2004;52(3):434-9.

19. Zuckerman IH, Langenberg P, Baumgarten M, et al. Inappropriate drug use and risk of transition to nursing homes among community-dwelling older adults. Med Care. 2006;44(8):722-30.

20. Lopez OL, Becker JT, Chang YF, et al. The long-term effects of conventional and atypical antipsychotics in patients with probable Alzheimer's disease. Am J Psychiatry. 2013;170(9):1051-8.

21. Bagchi AD, Esposito D, Verdier JM. Prescription drug use and expenditures among dually eligible beneficiaries. Health Care Financ Rev. 2007 Summer; 28(4):43-56.

22. Medicare Payment and Advisory Commission. A Data Book: Healthcare Spending and Medicare Program [online]. 2010 Available at: http://www.medpac.gov/documents/Jun10DataBook EntireReport.pdf. Accessed 3 Dec 2010.

23. Kaiser Commission on Medicaid and Uninsured. Dual Eligibles: medicaid role in filling the gaps [online]. Available at: http:// kaiserfamilyfoundation.files.wordpress.com/2013/01/dual-eligibles -medicaid-s-role-in-filling-medicare-s-gaps.pdf. Accessed 3 Dec 2010

24. Komisar HL, Feder J, Kasper JD. Unmet long-term care needs: an analysis of Medicare-Medicaid dual eligibles. Inquiry Summer. 2005;42(2):171-82.

25. Centers for Medicare and Medicaid Services. Medicaid Analytic eXtract (MAX) General Information [online]. Available at: http:// www.cms.hhs.gov/MedicaidDataSourcesGenInfo/07_MAXGeneral Information.asp. Accessed 3 Dec 2010.

26. Centers for Medicare and Medicaid Services. Medicare Standard Analytical Files: Identifiable Data Files [online]. Available at: http://www.cms.hhs.gov/IdentifiableDataFiles/02_StandardAnaly ticalFiles.asp. Accessed 3 Dec 2010.

27. Research Data Assistance Center (ResDAC): Available CMS Data [online]. Available at: http://www.resdac.umn.edu/ Available_CMS_Data.asp. Accessed 3 Dec 2010.

28. Ray W. Evaluating medication effects outside of clinical trials: new-user designs. Am J Epidemiol. 2003;158:915-20.

29. Aparasu RR, Chatterjee S, Mehta S, et al. Risk of death in dualeligible nursing home residents using typical or atypical antipsychotic agents. Med Care. 2012;50:961-9.

30. Brookhart MA, Schneeweiss S, Rothman KJ, et al. Variable selection for propensity score models. Am J Epidemiol. 2006;163:1149-56.

31. Parson LS. Reducing bias in a propensity score matched-pair sample using Greedy Matching Techniques [online]. Available at: http://www2.sas.com/proceedings/sugi26/p214-26.pdf. Accessed 3 Dec 2010.

32. Aparasu RR, Jano E, Johnson ML, et al. Hospitalization risk associated with typical and atypical antipsychotic use in community-dwelling elderly patients. Am J Geriatr Pharmacother. 2008;6(4):198-204.

33. Austin PC. Type I error rates, coverage of confidence intervals, and variance estimation in propensity-score matched analysis. Int J Biostats. 2009;5(1):1-21.

34. Alexander MT, Kufera JA. Butting heads on matched cohort analysis using SAS software. Available at: http://www.nesug.org/ proceedings/nesug07/sa/sa01.pdf. Accessed 3 Dec 2010.

35. Vittinghoff E, Glidden DV, Shiboski SC, et al. Regression methods in biostatistics: linear, logistic, survival and repeated measures models. New York, NY: Springer; 2005.

36. Kleinbaum DG. Survival analysis: a self-learning text. New York, NY: Springer; 1996. 
37. Masand PS. Side effects of antipsychotics in the elderly. J Clin Psychiatry. 2000;61(Suppl 8):43-9.

38. Kapur S, Remington G. Dopamine D2 receptors and their role in atypical antipsychotic action: still necessary and may even be sufficient. Biol Psychiatry. 2001;50(11):873-83.

39. Stahl SM. Describing an atypical antipsychotic: receptor binding and its role in pathophysiology. Primary Care Companion. J Clin Psychiatry. 2003;5(suppl 3):9-13.
40. Robins JM, Mark SD, Newey WK. Estimating exposure effects by modeling the expectation of exposure conditional on confounders. Biometrics. 1992;48:479-95. 